\title{
CONDUCTIVE SILVER FILMS ON PAPER PREPARED BY ATMOSPHERIC PRESSURE ARGON PLASMA CONVERSION OF SILVER NITRATE
}

\author{
1Július VIDA, ${ }^{2}$ Aleš STÝSKALÍK, 'Masoud SHEKARGOFTAR, ${ }^{3}$ Juho Antti SIRVIÖ, \\ ${ }^{1}$ Tomáš HOMOLA \\ ${ }^{1}$ Department of Physical Electronics, Faculty of Science, Masaryk University, Brno, Czech Republic, EU, \\ jvida@mail.muni.cz \\ ${ }^{2}$ Department of Chemistry, Faculty of Science, Masaryk University, Brno, Czech Republic, EU, \\ styskalik@chemi.muni.cz
}

${ }^{3}$ Fibre and Particle Engineering Research Unit, University of Oulu, Finland, EU, Juho.Sirvio@oulu.fi

https://doi.org/10.37904/nanocon.2020.3725

\begin{abstract}
We present a novel approach for deposition of metallic silver films from silver nitrate $\left(\mathrm{AgNO}_{3}\right)$ ink. The conversion of $\mathrm{AgNO}_{3}$ is induced by argon plasma of the diffuse coplanar surface barrier discharge (DCSBD) generated at atmospheric pressure. The macroscopically homogeneous and diffuse plasma of high power density allows fast reduction of $\mathrm{AgNO}_{3}$ into conductive metallic silver within two minutes. The process is carried out at temperatures below $70^{\circ} \mathrm{C}$ and without the need for a complex vacuum chamber and is therefore highly suitable for deposition onto temperature-sensitive materials. In our study we used paper prepared from nanocellulose fibres, which offers mechanical flexibility, translucency and recyclability while having lower surface roughness and enhanced mechanical properties and thermal stability compared to regular paper. As a figure of merit, the resistivity of prepared films was measured. The X-ray photoelectron spectroscopy was used to study the conversion of $\mathrm{AgNO}_{3}$ into metallic silver. Scanning electron microscopy revealed the morphology of the surface of the films giving insight on the nucleation and the growth process. The silver films prepared according to our methodology are an attractive possibility for applications in sensing devices or as conductive lines and other features in flexible electronics.
\end{abstract}

Keywords: Conductive films, silver nitrate, reduction, argon plasma, nanocellulose

\section{INTRODUCTION}

Printed electronics is an emerging technological field that focuses on utilizing deposition methods compatible with solution processing to prepare functional coatings for electronic devices. While conventional electronics are based on rigid substrates as silicon wafers; printed electronics aim towards flexible substrates such as polymer (PET, PEN) foils or (nano)paper, which can be designed for the highly desirable roll-to-roll processing with high throughput.

Printing of the metals is essential to create conductive features and paths in electronic circuits. There are several approaches for the formulation of metal inks for printing. Nanoparticle inks are the most studied in the metal ink technology [1]. Nanoparticles are dispersed within an organic solution together with some capping agents to control their shape and size. Another approach is formulation of particle-free inks, where metals exist in a form of ions from metal-metorganic complexes dissolved in volatile solvents. After printing the complexes can be transformed into pure metal patterns by decomposition at elevated temperature [2] or by chemical reduction [3]. 
Of particular interest are metal particle-free inks based on inorganic metal salts [4]. They have the same advantages against NP inks as the metal-organic complex inks, while the metal salts are readily available and do not require careful design and synthesis. Numerous metals have been printed by simple dissolving of the metal salt in water with addition of volatile organic solvents to adjust the fluid properties of the inks including gold, silver, copper, palladium, platinum, lead, bismuth and tin [5]. The drawback of metal salt inks is relatively high sintering temperature required for the decomposition.

Post-deposition sintering is typically required for removal of the organic parts of the inks that decrease the conductivity of the printed films. In case of particle-free inks the sintering is also needed for the conversion of the ionic metals to pure metal films. Sintering at elevated temperatures restricts the possible substrates used, as polymers or paper often cannot withstand temperatures exceeding $100{ }^{\circ} \mathrm{C}$. Alternative sintering approaches have therefore been used such as photonic sintering [6], microwave sintering [7], chemical sintering [8] and plasma sintering [5,9-11].

In this contribution we present a method to prepare conductive silver films by reduction of silver nitrate $\mathrm{AgNO}_{3}$ printed from a simple water-based ink by plasma treatment at low temperature $\left(<70{ }^{\circ} \mathrm{C}\right)$ at atmospheric pressure. The approach we present can completely convert silver nitrate film into pure metallic silver in just two minutes. It is highly suitable for printing on temperature-sensitive substrates and is capable of fast treatment of large areas and is compatible with roll-to-roll processing.

As a substrate we used nanocellulose paper. Compared to naturally-occurring cellulose, which consists of cellulose fibres 20-50 $\mu \mathrm{m}$ in diameter, the microfibrils that make up nanocellulose paper have diameters that lie in a measurement range of only tens of nanometres. This allows nanocellulose paper to match the desirable properties of plastic substrates, such as low surface roughness and thermal stability, while adding recyclability and enhanced flexibility $[12,13]$.

\section{EXPERIMENTAL PROCEDURE}

\subsection{Materials}

Silver nitrate was purchased from Merck $K G a A$ (Germany). By dissolving $0.212 \mathrm{~g}$ of $\mathrm{AgNO}_{3}$ in a mixture of $0.429 \mathrm{~g}$ water and $0.946 \mathrm{~g}$ ethylene glycol (Lach-ner s.r.o, Czech Republic) we obtained an ink with 15 wt.\% of $\mathrm{AgNO}_{3}$. The ink was very stable and retained its properties after up to a year of storage.

The nanocellulose paper was kindly provided by Dr. Juho Antti Sirviö of the Fibre and Particle Engineering Research Unit at the University of Oulu, Finland. The preparation process is thoroughly described in the works of Sethi et. al. and Li et. al. [14,15].

\subsection{Deposition and plasma treatment}

We deposited the silver nitrate ink using a spin-coater. A droplet with volume of $10 \mu \mathrm{l}$ was placed in the middle of a $0.5 \mathrm{~cm} \times 0.5 \mathrm{~cm}$ square nanocellulose substrate and spun for $45 \mathrm{~s}$ at 2000 RPM to distribute the ink.

Immediately after the deposition the coated samples were attached to the sample holder by a double-sided tape and inserted into the gas chamber, schematically visualized in Figure 1. The gas chamber had a volume of $50 \mathrm{~cm}^{3}$. An argon gas was continually flowing through the gas chamber at a rate of $1 \mathrm{l} / \mathrm{min}$ to achieve an argon atmosphere inside the chamber. The chamber was operated at atmospheric pressure. Plasma was generated by diffuse coplanar surface barrier discharge (DCSBD) - a dielectric barrier discharge withcoplanar arrangement of electrodes; commercialized by Roplass s.r.o. (Czech republic) [16].

The plasma region of the DCSBD unit was around $0.3 \mathrm{~mm}$ thick. To ensure a good contact of the sample surface with the plasma region the sample holder was distanced from the ceramics of the DCSBD unit by $0.3 \mathrm{~mm}$ of Kapton tape. The exposure time of the treated sample surface was varied from $0 \mathrm{~s}$ to $128 \mathrm{~s}$. 


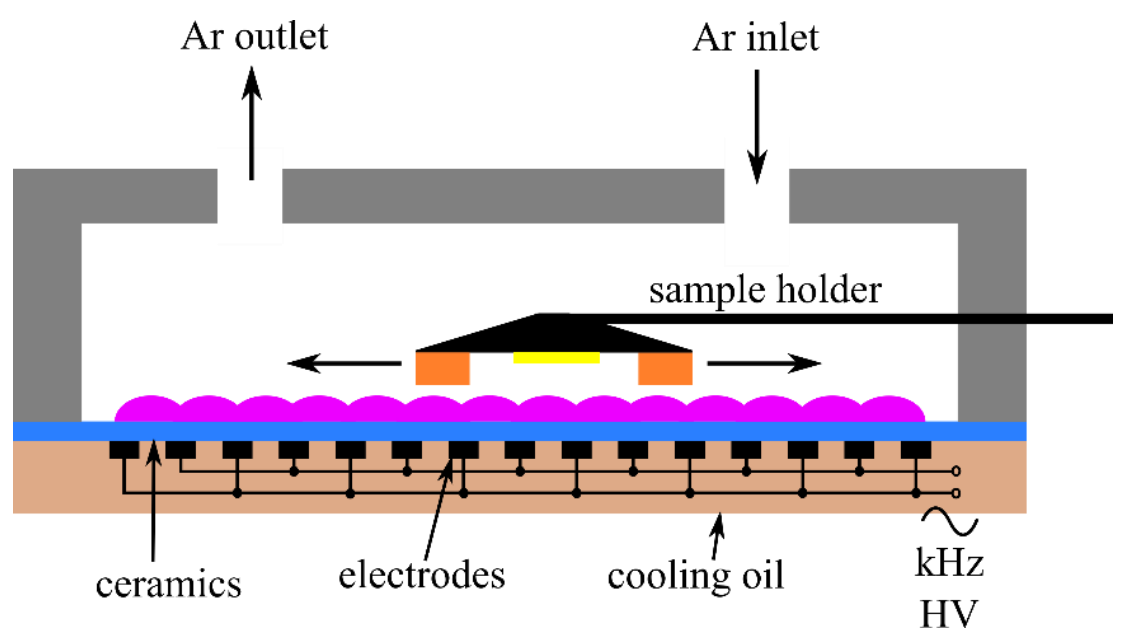

Figure 1 Scheme of the setup of the DCSBD plasma unit operating in argon. Samples are attached to the sample holder, which can be moved horizontally over the plasma region to achieve a uniform treatment.

\subsection{Film analysis}

Mira3 scanning electron microscope (SEM) from Tescan (Czech Republic) was employed for the analysis of the morphology of the reduced silver film and the evaluation silver nanoparticles dimension. The images were captured at with $20 \mathrm{x}$ up to $100 \mathrm{x}$ magnification, $5 \mathrm{kV}$ accelerating voltage and at a working distance of $5 \mathrm{~mm}$.

The surface chemistry of the reduced silver films was determined from X-ray photoelectron spectra (XPS) obtained by AXIS Supra spectrometer from Kratos Analytical Ltd. (United Kingdom). The instrument uses Al Ka spectral line (1486.6 eV photon energy) and an electron flood gun was utilized for charge compensation. The acquisition of narrow regions of the spectrum was performed with the pass energy $20 \mathrm{eV}$. For analysis of the spectra CasaXPS software was used. The spectra were calibrated to $\mathrm{C}-\mathrm{C} / \mathrm{C}-\mathrm{H}$ peak of $\mathrm{C} 1 \mathrm{~s}$ at $284.8 \mathrm{eV}$ binding energy.

The sheet resistance of the reduced silver films was determined by the four-point probe measurement using the Four-Point Probe System from Ossila Ltd (United Kingdom).

\section{RESULTS AND DISCUSSION}

The sheet resistance of the as-deposited $\mathrm{AgNO}_{3}$ film and the converted silver films after treatment for $16 \mathrm{~s}$, $64 \mathrm{~s}$ and $128 \mathrm{~s}$ are shown in Table 1. Because of the insulating nature of the $\mathrm{AgNO}_{3}$ caused the sheet resistance of the reference sample was too high to be measured. With increasing exposure to the reduction atmosphere of the argon plasma the sheet resistance of the film decreased down to $0.6 \pm 0.1 \Omega / \square$ for the film treated for $128 \mathrm{~s}$. The energetic species in the plasma, specifically the argon ions and electrons are thought to be responsible for the conversion of the $\mathrm{AgNO}_{3}$ into metallic silver. The plasma has a limited penetration depth into the treated film given by the porosity of the substrate and the film. There is a possibility that the converted metallic silver film forms a crust around non-converted $\mathrm{AgNO}_{3}$ below, that has not been exposed to the plasma species.

The XPS spectra of the film treated for $128 \mathrm{~s}$ were analysed for the atomic concentrations and displayed $48 \%$ of silver, $35 \%$ of carbon, $14 \%$ of oxygen and $3 \%$ of fluorine. The carbon and oxygen that were detected can be attributed to surface contamination as well as the signal from the underlying nanocellulose substrate, which can be significant due to its porosity. The fluorine signal was also detected in the XPS spectra of the nanocellulose without the coating, therefore it can be attributed to the substrate as well. Interestingly, no nitrogen was detected in the coating. This suggests complete removal of the $\mathrm{AgNO}_{3}$ during the conversion process. 
Table 1 Sheet resistance of as-deposited $\mathrm{AgNO}_{3}$ reference film and plasma reduced silver films

\begin{tabular}{|c|c|}
\hline Treatment time & Sheet resistance $[\Omega / \square]$ \\
\hline Reference & $\mathrm{n} / \mathrm{a}(>10 \mathrm{M} \Omega / \square)$ \\
\hline $16 \mathrm{~s}$ & $160 \pm 30$ \\
\hline $64 \mathrm{~s}$ & $50 \pm 20$ \\
\hline $128 \mathrm{~s}$ & $0.6 \pm 0.1$ \\
\hline
\end{tabular}

The narrow XPS region of the $\mathrm{Ag} 3 \mathrm{~d} 5 / 2$ of the $128 \mathrm{~s}$ treated sample is shown in Figure 2a. A metallic $\mathrm{Ag}$ displays a single peak at around $368.4 \mathrm{eV}$ and the signal from $\mathrm{AgNO}_{3}$ is typically shifted by $0.4 \mathrm{eV}$ towards higher binding energies. This small difference in the binding energies makes it difficult to assess the chemical form of the film. If we look at the Ag MNN auger peak in Figure $\mathbf{2} \mathbf{b}$ we can better see the pronounced features typical for the metallic silver rather than those in the position for the $\mathrm{AgNO}_{3}$ [17].
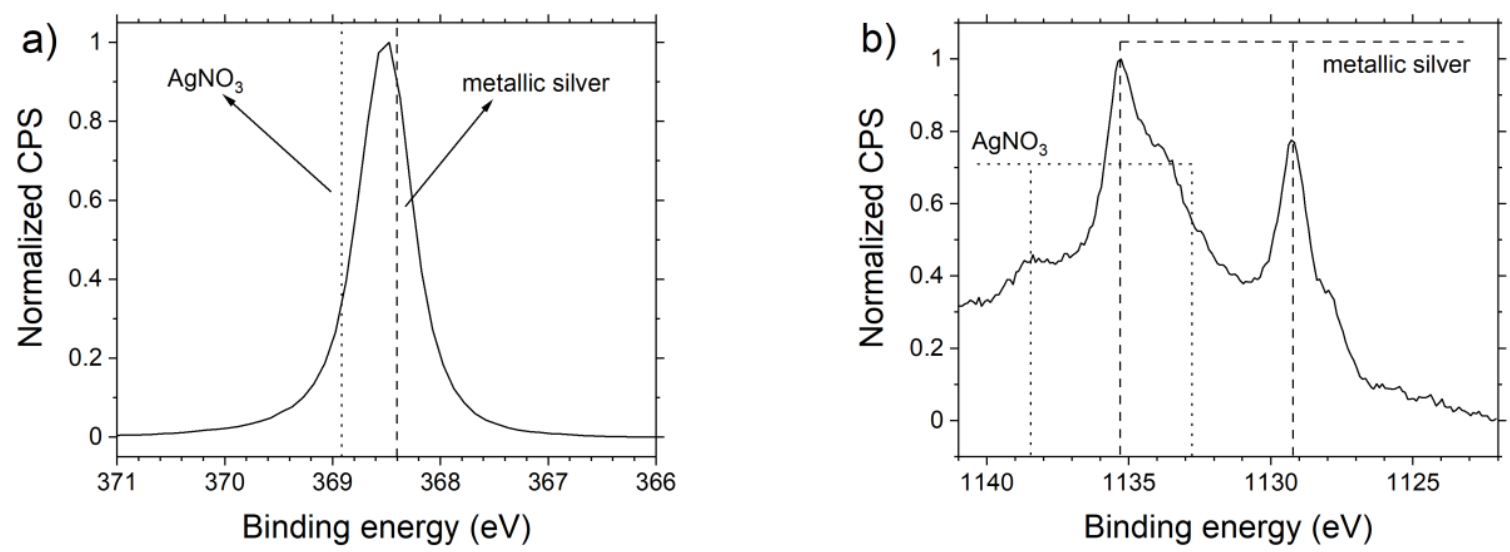

Figure 2 Narrow XPS regions of the film treated for $128 \mathrm{~s}$ a) Ag 3d 5/2 peak b) Ag MNN auger peak

The SEM images of the film treated for $128 \mathrm{~s}$ are shown in Figure 3. The image with lower magnification in Figure 3a shows the homogeneity of the converted film. The reduced silver film copies the fibres of the underlying nanocellulose substrate. The image with higher magnification in Figure $\mathbf{3 b}$ shows details of the nanoparticles of silver which formed by agglomeration of silver atoms during the conversion from $\mathrm{AgNO}_{3}$ by plasma. The average diameter of nanoparticles was $36 \pm 1 \mathrm{~nm}$. The tight packing of the nanoparticles that can be seen in Figure $\mathbf{3 b}$ and the necks that formed between them explain the excellent sheet resistance of the film.
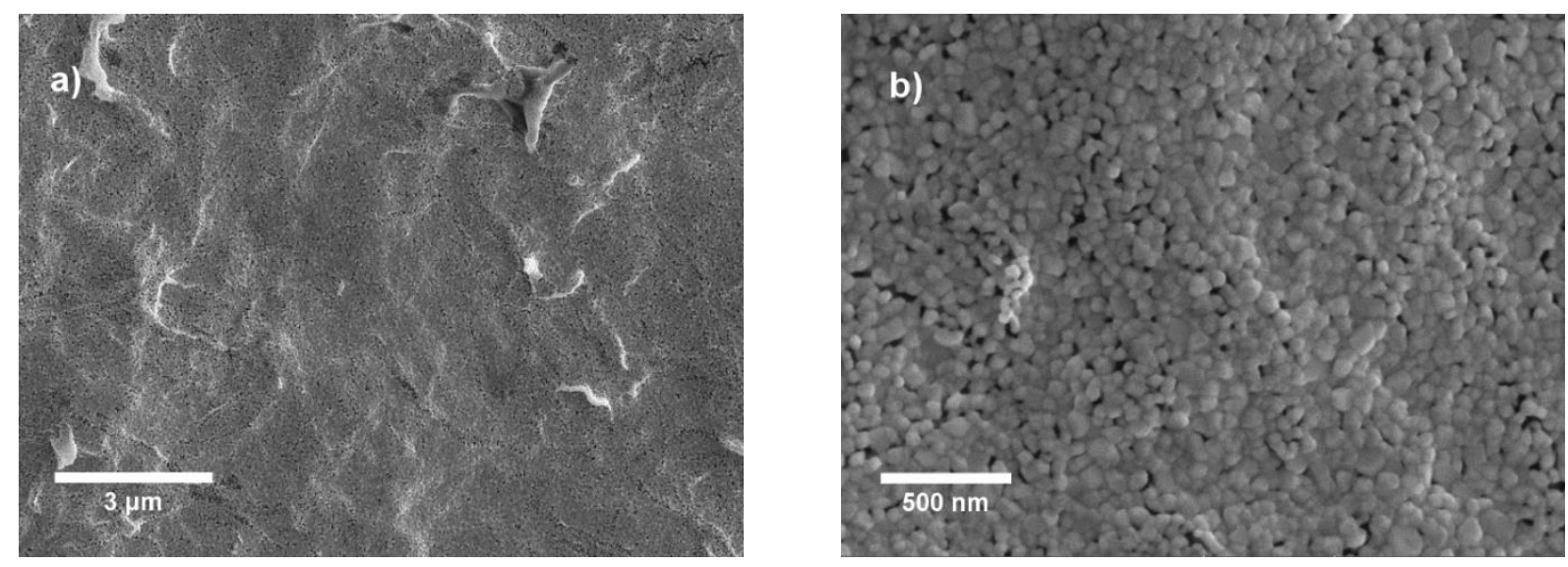

Figure 3 SEM images of the reduced silver film after $128 \mathrm{~s}$ treatment with a) $20 \mathrm{kx}$ magnification and b) $100 \mathrm{kx}$ magnification 


\section{CONCLUSION}

Silver nitrate dissolved in a mixture of water and ethylene glycol was printed using spin-coating on the nanocellulose substrate. Exposure of the printed film to the argon plasma generated by the diffuse coplanar surface barrier discharge led to the conversion of the silver salt to metallic silver as a result of reduction by energetic species from the plasma, specifically electrons and argon ions. The sheet resistance of $0.6 \Omega / \square$, which is about 10x the resistance of bulk silver, was achieved after treatment for just $128 \mathrm{~s}$. X-ray photoelectron spectroscopy suggested a complete conversion of the $\mathrm{AgNO}_{3}$, as there was no nitrogen detected on the surface and the auger peak of silver displayed a shape typical for metallic silver, not a mixture of silver and silver nitrate. The nanocellulose paper substrate was used because of its compatibility with the ink, good mechanical and thermal properties and it's flexibility and recyclability. Scanning electron microscopy images showed homogeneous coating copying the rough surface of the nanocellulose. The agglomerated nanoparticles were densely packed and formed connections during conversion. The high conductivity of the prepared films and the compatibility with the roll-to-roll processing makes this method very attractive for applications in flexible and printed electronics.

\section{ACKNOWLEDGEMENTS}

This research has been supported by Czech Science Foundation project 19-14770Y and projects LM2018097 and LM2018110 funded by Ministry of Education, Youth and Sports of Czech Republic.

\section{REFERENCES}

[1] RAJAN, K., ROPPOLO, I., CHIAPPONE, A., BOCCHINI, S., PERRONE, D., CHIOLERIO, A. Silver nanoparticle ink technology: State of the art. Nanotechnology, Science and Applications. 2016, vol. 9, pp. 1-13.

[2] SMITH, P. J., SHIN, D. Y., STRINGER, J. E., DERBY, B., REIS, N. Direct ink-jet printing and low temperature conversion of conductive silver patterns. Journal of Materials Science. 2006, vol. 41, no. 13, pp. 4153-4158.

[3] BLACK, K., SINGH, J., MEHTA, D., SUNG, S., SUTCLIFFE, C. J., CHALKER, P. R. Silver Ink Formulations for Sinter-free Printing of Conductive Films. Scientific Reports. 2016, vol. 6, pp. 1-7.

[4] SUI, Y., KREIDER, L. P., BOGIE, K. M., ZORMAN, C. A.. Fabrication of a silver-based thermistor on flexible, temperature-sensitive substrates using a low-temperature inkjet printing technique. IEEE Sensors Letters. 2019, vol. 3, no. 2 .

[5] SUI, Y., DAI, Y., LIU, C. C., SANKARAN, R. M., ZORMAN, C. A. A New Class of Low-Temperature PlasmaActivated, Inorganic Salt-Based Particle-Free Inks for Inkjet Printing Metals. Advanced Materials Technologies. 2019, vol. 4, no. 8.

[6] MAEKAWA, K., YAMASAKI, K., NIIZEKI, T., MITA, M., MATSUBA, Y., TERADA, N., SAITO, H. Drop-onDemand Laser Sintering With Silver Nanoparticles for Electronics Packaging. IEEE TRANSACTIONS ON COMPONENTS, PACKAGING AND MANUFACTURING TECHNOLOGY. 2012, vol. 2, no. 5.

[7] PERELAER, J., DE GANS, B. J., SCHUBERT, U. S., Ink-jet printing and microwave sintering of conductive silver tracks. Advanced Materials. 2006, vol. 18, no. 16, pp. 2101-2104

[8] SHI, L., LAYANI, M., CAI, X., ZHAO, H., MAGDASSI, S., LAN, M., An inkjet printed Ag electrode fabricated on plastic substrate with a chemical sintering approach for the electrochemical sensing of hydrogen peroxide. Sensors and Actuators, B: Chemical. 2018, vol. 256, pp. 938-945.

[9] KNAPP, C. E., CHEMIN, J. B., DOUGLAS, S. P., ONDO, D. A., GUILLOT, J., CHOQUET, P., BOSCHER, N. D., Room-Temperature Plasma-Assisted Inkjet Printing of Highly Conductive Silver on Paper. Advanced Materials Technologies. 2018, vol. 3, no. 3.

[10] WÜNSCHER, S., STUMPF, S., TEICHLER, A., PABST, O., PERELAER, J., BECKERT, E., SCHUBERT, U. S., Localized atmospheric plasma sintering of inkjet printed silver nanoparticles. Journal of Materials Chemistry. 2012, vol. 22, no. 47, pp. 24569-24576.

[11] MA, S., BROMBERG, V., LIU, L., EGITTO, F. D., CHIAROT, P. R., SINGLER, T. J., Low temperature plasma sintering of silver nanoparticles. Applied Surface Science. 2014, vol. 293, pp. 207-215. 
[12] ZHU, H., LUO, W., CIESIELSKI, P. N., FANG, Z., ZHU, J. Y., HENRIKSSON, G., HIMMEL, M. E., HU, L. WoodDerived Materials for Green Electronics, Biological Devices, and Energy Applications. Chemical Reviews. 2016, vol. 116, no. 16, pp. 9305-9374.

[13] ZHU, H., FANG, Z., PRESTON, C., LI, Y., HU, L. Transparent paper: Fabrications, properties, and device applications. Energy and Environmental Science. 2014, vol. 7, no. 1, pp. 269-287.

[14] SETHI, J., FAROOQ, M., SAIN, S., SAIN, M., SIRVIÖ, J. A., ILLIKAINEN, M., OKSMAN, K. Water resistant nanopapers prepared by lactic acid modified cellulose nanofibers. Cellulose. 2018, vol. 25, no. 1, pp. $259-268$.

[15] LI, P., SIRVIÖ, J. A., HONG, S., ÄMMÄLÄ, A., LIIMATAINEN, H., Preparation of flame-retardant lignin-containing wood nanofibers using a high-consistency mechano-chemical pretreatment. Chemical Engineering Journal. 2019, vol. 375.

[16] ČERNÁK, M., ČERNÁKOVÁ, L'., HUDEC, I., KOVÁČIK, D., ZAHORANOVÁ, A. Diffuse coplanar surface barrier discharge and its applications for in-line processing of low-added-value materials. EPJ Applied Physics. 2009, vol. 47 , no. 2 .

[17] FERRARIA, A. M., CARAPETO, A. P., BOTELHO DO REGO, A. M. X-ray photoelectron spectroscopy: Silver salts revisited. Vacuum. 2012, vol. 86, no. 12, pp. 1988-1991. 